\title{
Pengembangan Instrumen Penilaian Kemampuan Berpikir Kritis Siswa SD pada Mata Pelajaran PPKn
}

\author{
Kadek Perdinna Tri Astiwi ${ }^{1}$, Putu Aditya Antara ${ }^{2}$, I Gusti Ayu Tri Agustiana ${ }^{3}$ \\ 1,2,3 Program Studi Pendididkan Guru Sekolah Dasar, Universitas Pendidikan Ganesha, Bali, Indonesia \\ *Corresponding author: perdinnatriastiwi@gmail.com
}

\begin{abstract}
Abstrak
Penelitian ini bertujuan untuk mendeskripsikan validitas dan reiabilitas instrumen penilaian kemampuan berpikir kritis siswa pada mata pelajaran PPKn materi hak kewajiban dan tanggung jawab kelas V SD. Penelitian ini berjenis penelitian pengembangan (Research and Development) dengan menggunakan model RDR (Research Development Research) Subyek dalam penelitian ini adalah instrumen penilaian kemampuan berpikir kritis pada mata pelajaran PPKn yang berupa kisi-kisi instrumen, penilaian tes dalam bentuk uraian dengan jumlah soal sebanyak 20 butir serta rubrik penilaian. Instrumen kemampuan berpikir kritis ini telah diuji oleh dua orang pakar/ahli untuk mengukur validitas dan reliabilitas. Dari hasil analisis uji validitas isi didapatkan hasil sebesar 1.00 yang berada pada kategori sangat tinggi, dan berdasarkan uji validitas butir diperoleh nilai tiap butir instrumen yaitu $r$ hitung $>r_{\text {tabel. }}$ Sehingga keseluruhan butir instrumen dinyatakan valid. Serta hasil analisis uji reliabilitas instumen kemampuan berpikir kritis sebesar 0.84 dengan kriteria reliabilitas sangat tinggi.
\end{abstract}

Kata kunci: berpikir kritis, PPKn, instrumen penilaian.

\section{Abstract}

This study aims to describe the validity and reliability of the students' critical thinking skills assessment instruments on PPKn subjects in the rights and responsibilities of class $V$ of SD Academic Year. This research is a type of research and development by using the RDR (Research Development Research) model. The subject in this study is an instrument of critical thinking skills assessment in PPKn subjects in the form of instrument lattices, test assessments in the form of descriptions with a total of 20 questions items and assessment rubrics. The instrument of critical thinking ability has been tested by two experts to measure the validity and reliability. From the results of the analysis of the content validity test, it was found that the result was 1.00 which was in the very high category, and based on the item validity test, the value of each item was obtained, namely $r$ arithmetic > $r$ table. So that the entire instrument is declared valid. And the results of the analysis of the instrument reliability test of critical thinking skills of 0.84 with very high reliability criteria

Keywords: critical thinking, PPKn, assessment instruments

\section{Introduction}

Pendidikan merupakan salah satu kebutuhan manusia yang penting karena pendidikan mempunyai tugas untuk menyiapkan sumber daya manusia yang baik bagi pembangunan bangsa dan negara. Penyelenggaraan pendidikan saat ini lebih mengutamakan proses pembelajaran yang terintegrasi, guru hendaknya dapat mengembangkan potensi anak secara maksimal untuk berbagai kemampuan dalam memecahkan masalah dalam kehidupan di masa depan (Antara, 2018; Suciasih et al., 2019). Dalam dunia pendidikan di Indonesia, khususnya pada jenjang sekolah dasar (SD) terdapat lima mata pelajaran wajib yang diterapkan antara lain IPA, IPS, Bahasa Indonesia, Pendidikan Pancasila dan Kewarganegaraan (PPKn), dan Matematika. PPKn merupakan mata pelajaran yang digunakan sebagai wahana untuk

$\begin{array}{lll}\text { History: } & & \text { Publisher: Undiksha Press } \\ \text { Received } & : 2 \text { September } 2020 & \text { Licensed: This work is licensed under } \\ \text { Revised } & : 11 \text { September } 2020 & \text { a Creative Commons Attribution 3.0 License } \\ \text { Accepted } & : 20 \text { October } 2020 & \end{array}$


mengembangkan dan melestarikan nilai luhur dan moral yang berakar pada budaya bangsa (Ahmad, 2013; Wibowo \& Wahono, 2017). PPKn juga memfokuskan pada pembentukan warga negara yang memahami dan mampu melaksanakan hak-hak dan kewajiban warga negara indonesia yang cerdas, terampil, dan berkarakter yang diamanatkan oleh pancasila dan UUD 1945 (Lestari et al., 2013; Suwandi \& Julianto, 2017). Hal ini nantinya diharapkan mampu mengarah pada suatu masyarakat yang menempatkan demokrasi dalam kehidupan berbangsa yang berlandaskan pada Pancasila, Undang-undang Dasar, dan norma-norma yang berlaku di masyarakat.

Pembelajaran PPKn yang dilakukan di sekolah tidak hanya mencakup hafalan dan pemahaman, tetapi juga mencakup kemampuan berpikir kritis. Menurut Siswono, berpikir kritis termasuk salah satu perwujudan pemikiran tingkat tinggi (high order thinking) (Amir, 2015; Dinni, 2018). Selain itu, berpikir kritis juga termasuk kedalam kemampuan kognitif dalam pengambilan kesimpulan berdasarkan alasan yang logis dan bukti empiris (A. I. Wijayanti et al., 2015). Para pemikir kritis selalu melalui beberapa tahapan dalam tindakannya yaitu merumuskan masalah, memberikan argumen, melakukan dedukasi, melakukan induksi, melakukan evaluasi dan mengambil keputusan untuk mengambil tindakan (Jufri, 2013). Dengan kemampuan ini, siswa diharapkan mampu merespon persoalan sosial yang mereka jumpai dalam kehidupan sehari-hari.

Untuk mengetahui kemampuan berpikir kritis yang dimiliki oleh setiap siswa diperlukan suatu penilaian disetiap akhir pembelajaran. Penilaian merupakan teknik untuk memperoleh informasi tentang kemajuan peserta didik di sekolah (Arifin, 2009). Penilaian juga merupkan suatu proses pengumpulan data siswa yang dilakukan selama proses pembelajaran yang kemudian dianalisis. Hasil analisis tersebut kemudian dapat digunakan sebagai umpan balik (feedback) terhadap pembelajaran ataupun sebagai bahan pengambilan keputusan terhadap status siswa. Pada dasarnya, penilaian berperan sebagai program evaluasi proses, kemajuan belajar dan hasil belajar siswa (Docktor \& Heller, 2009; Mahdiansyah, 2019). Instrumen penilaian dapat dibagi menjadi dua yaitu instrumen tes dan instrumen non tes. Instrumen tes merupakan alat ukur yang berisi pernyataan atau soal yang harus dijawab dengan tepat. Yusuf (2015) Tes merupakan suatu prosedur yang sepesifik yang digunakan untuk mengukur tingkah lakau seseorang. Instrumen non tes adalah penilaian yang dilakukan tanpa menguji peserta didik tetapi dengan melakukan pengamatan secara sistematis. (Dilla, 2019) Penilaian non tes merupakan penilaian yang mengukur kemampuan siswa secara langsung dengan memberikan tugas-tugas secara nyata dalam kegiatan pembelajaran.

Pendidikan Pancasila dan Kewarganegaraan (PPKn) sangat penting dibelajarkan pada siswa SD untuk membentuk karakteristik dan kepribadian siswa yang cerdas sejak dini (Nusarastriya, 2013). Pembelajaran PPKn merupakan komponen pebelajaran yang memfokuskan siswa untuk memahami dan melaksanakan hak-hak dan kewajiban untuk menjadi warga negara yang cerdas dan berkarakter. Pembelajaran PPKn yaitu usaha sadar yang dilakukan secara ilmiah untuk memberikan kemudahan belajar pada siswa agar terjadinya internalisasi moral Pancasila dan pengetahuan untuk melandasi tujuan pendidikan nasional yang diwujudkan dalam perilaku sosial sehari-hari (Suhartono, 2018).

Pelaksanaan pembelajaran PPKn sangat penting untuk dibelajarkan kepada siswa SD untuk meningkatkan kesadaran siswa menjadi warga negara yang baik sejak dini (Nurmalisa et al., 2020). Tujuan Pendidikan Kewarganegaran adalah Partisipasi yang penuh nalar serta tanggung jawab dalam kehidupan politik dari warga negara yang taat pada nilai-nilai juga prinsip dasar demokrasi konstitusional Indonesia. Partisipasi warga negara yang efektif serta penuh tanggung jawab memerlukan penguasaan seperangkat ilmu pengetahuan, keterampilan intelektual dan keterampilan untuk berperan serta. Penelitian ini bertujuan untuk mendeskripsikan validitas dan reiabilitas instrumen penilaian kemampuan berpikir kritis siswa pada mata pelajaran PPKn materi hak kewajiban dan tanggung jawab kelas V SD. 


\section{Materials and Methods}

Penelitian ini menggunakan jenis penelitian pengembangan dengan menggunakan model RDR yang dikembangkan oleh Brog \& Gall. Penelitian ini bertujuan untuk mengembangkan produk yang sudah ada ataupun menghasilkan produk baru. Dalam penelitian ini, produk yang akan dihasilkan adalah instrumen penilaian. Subyek dalam penelitian ini adalah instrumen penilaian kemampuan berpikir kritis pada mata pelajaran PPKn yang berupa penilaian tes dalam bentuk uraian atau essay dengan jumlah soal 20 butir. Variabel bebas dalam penelitian ini adalah instrumen penilaian, sedangkan variabel terikatnya yaitu kemampuan berpikir kritis siswa pada mata pelajaran PPKn. Prosedur pengembangan dilakukan dengan tahapan-tahapan sebagai berikut: 1) Research (study pendahulu), 2) Development (pengembangan), 3) Research (uji efektivitas). Uji coba dilakukan dengan melibatkan seluruh siswa kelas V SD Negeri 1 Bebetin, SD Negeri 3 Bebetin dan SD Negeri 5 Bebetin.

Pengumpulan data pada penelitian ini menggunakan metode tes dalam bentuk tes essay atau uraian. Sedangkan instrumen yang digunakan dalam penelitian ini yaitu instrumen tes yang berisi pernyataan atau soal-soal yang harus dijawab dengan tepat oleh siswa dengan kisikisi instrumen kemampuan berpikir kritis seperti yang dijabarkan pada Tabel 1. Pengumpulan data pada penelitian ini menggunakan metode tes dalam bentuk tes essay atau uraian. Sedangkan instrumen yang digunakan dalam penelitian ini yaitu instrumen tes yang berisi pernyataan atau soal-soal yang harus dijawab dengan tepat oleh siswa dengan kisi-kisi instrumen kemampuan berpikir kritis seperti yang dijabarkan pada Tabel 1.

Tabel 1. Kisi-Kisi Instrumen

\begin{tabular}{|c|c|c|c|c|c|}
\hline No & $\begin{array}{c}\text { Aspek/Dimensi } \\
\text { Kemampuan } \\
\text { Berpikir Kritis }\end{array}$ & Indikator Soal & $\begin{array}{c}\text { Ranah } \\
\text { Kognit } \\
\text { if }\end{array}$ & $\begin{array}{c}\text { No } \\
\text { soal }\end{array}$ & $\begin{array}{l}\text { Jumla } \\
\text { h Soal }\end{array}$ \\
\hline
\end{tabular}

1 1.Menganalisis argumen

2. Mengidentifikasi istilah dan menilai suatu dimensi

3. Memutuskan sebuah tindakan
1.1. Memberikan alasan perlu melakukan tanggung jawab dan kewajiban di rumah dalam kehiupan sehari-hari

1.2. Menganalisis bentuk tanggung jawab sebagai warga dan siswa dalam kehidupan sehari-hari.

C5

$5,7 \quad 2$

C4

15 ,

16

2

2.1. Menganalisis bentuk pelanggaran hak sebagai warga dan siswa dalam kehidupan sehari-hari

C4 $2,18 \quad 2$

3.1. Menganalisis akibat yang timbul karena tidak adanya penerapan tanggung jawab di sekolah dan masyarakat

C4 $\quad \begin{array}{ll}10, \\ 11,\end{array} \quad 3$

3.2 Menganalisis akibat yang timbul karena tidak adanya penerapan kewajiban di masyarakat 


\begin{tabular}{|c|c|c|c|c|c|}
\hline No & $\begin{array}{l}\text { Aspek/Dimensi } \\
\text { Kemampuan } \\
\text { Berpikir Kritis }\end{array}$ & Indikator Soal & $\begin{array}{l}\text { Ranah } \\
\text { Kognit } \\
\text { if }\end{array}$ & $\begin{array}{l}\text { No } \\
\text { soal }\end{array}$ & $\begin{array}{l}\text { Jumla } \\
\text { h Soal }\end{array}$ \\
\hline \multirow{2}{*}{\multicolumn{2}{|c|}{$\begin{array}{l}\text { 4. Menginduksi atau } \\
\text { menyimpulkan }\end{array}$}} & $\begin{array}{l}\text { 4.1 Menyimpulkan bentuk } \\
\text { kewajiban sebagai warga dan } \\
\text { siswa dalam kehiupan sehari- } \\
\text { hari }\end{array}$ & $\mathrm{C} 5$ & 8,17 & 2 \\
\hline & & $\begin{array}{l}\text { 4.2 Menyimpulkan hak dan } \\
\text { tanggung jawab sebagai warga } \\
\text { dalam kehidupan sehari-hari }\end{array}$ & C5 & 1,19 & 2 \\
\hline & $\begin{array}{l}5 . \\
\text { Mempertimbangka } \\
\text { n suatu laporan } \\
\text { hasil observasi }\end{array}$ & $\begin{array}{l}\text { 5.1. Membandingkan kewajiban } \\
\text { dan tanggung jawab dalam } \\
\text { kehidupan sehari-hari } \\
\text { berdasarkan teks cerita }\end{array}$ & $\mathrm{C} 5$ & 4,6 & 2 \\
\hline & & $\begin{array}{l}\text { 5.2. Merumuskan hak dan } \\
\text { tanggung jawab sebagai warga } \\
\text { dalam kehidupan sehari-hari }\end{array}$ & C6 & $\begin{array}{l}3,9 \\
20\end{array}$ & 3 \\
\hline
\end{tabular}

Analisis yang dilakukan terhadap data-data yang telah diperoleh meliputi analisis validitas instrumen dan reliabilitas instrumen. Dalam analisis validitas intrumen, dilakukan dua pengujian yakni validitas isi dan uji validitas butir. Adapun uji validitas isi instrumen sekala kemampuan berpikir kritis menggunakan rumus Gregory (Candiasa, 2010; Kahar, 2017) dimana vi merupakan validitas isi, A menunjukkan bahwa kedua judges tidak setuju, B menunjukkan judges 1 tidak setuju tapi judges 2 setuju, $\mathrm{C}$ menunjukkan judges 1 setuju dan judges 2 tidak setuju, sedangkan D menunjukksn keduanya tidak setuju.

Uji validitas butir menggunakan teknik korelasi product moment dimana $\mathrm{r}_{\mathrm{xy}}$ adalah koefisien korelasi product moment, $\mathrm{X}$ merupakan skor responden untuk butir yang validitasnya ditentukan, $\mathrm{Y}$ menunjukkan skor total responden, dan $\mathrm{N}$ adalah jumlah responden atau peserta tes. Uji reliabilitas hanya dilakukan terhadap butir soal yang valid dengan menggunakan persamaan Alpha Cronbach. Dimana $\mathrm{r}_{11}$ merupakan koefisien reliabilitas instrumen, $\mathrm{n}$ adalah jumlah butir item yang valid, $\Sigma \sigma_{\mathrm{i}}{ }^{2}$ menunjukkan jumlah varian skor tiap butir, dan $\Sigma \sigma_{\mathrm{t}}{ }^{2}$ menunjukkan varian total.

\section{Results and Discussion Hasil Penelitian}

Uji validitas isi berkaitan dengan isi dan format dari instrumen penilaian. Agar validitas isi dari instrumen terpenuhi, maka dilakukan penilaian butir-butir tes yang telah ditulis oleh dua pakar (expert judgment) yang telah ditunjuk. Kegiatan penelaahan tes disertai kisi-kisi, kunci jawaban dan rubrik penskoran. Pakar yang terlibat dalam kegiatan ini adalah pakar pembelajaran PPKn. Dalam penelaahan ini digunakan pedoman penelaahan (lembar validasi) yang diserahkan kepada validator. Lembar validasi tersebut disusun berdasarkan kaedah penulisan tes tertulis yang mencakup materi, konstruksi, dan bahasa. Dua orang ahli isi (judges) yang ditunjuk antara lain Ni Wayan Eka Widiastini, S.Pd., M.Pd sebagai judges I dan Kadek Yudiana, S.Pd., M.Pd. sebagai (judges) II. Selanjutnya butir-butir pernyataan baik yang relevan maupun tidak relevan dimasukan kedalam Tabel 2 
Tabel 2. Matriks tabulasi instrumen

\begin{tabular}{lcll}
\hline \multicolumn{2}{c}{ Pakar 1 } & \multicolumn{2}{c}{ Pakar 2 } \\
\hline \multicolumn{1}{c}{ Relevan } & Tidak Relevan & \multicolumn{1}{c}{ Relevan } & Tidak Relevan \\
\hline $1,2,3,4,5,6,7,8$, & - & $1,2,3,4,5,6,7,8,9$, & - \\
$9,10,11,12,13,14$, & & $10,11,12,13,14,15$, & \\
$15,16,17,18,19$, & & $16,17,18,19,20$ & \\
20 & & & \\
\hline
\end{tabular}

Perhitungan validitas isi dilakukan dengan formula Gregory pada persamaan. Berdasarkan dari hasil perhitungan kedua judges diperoleh hasil sebesar 1.00. Hal ini menunjukan bahwa skor hasil uji pakar berada pada kategori sangat tinggi Dengan demikian, maka instrumen penilaian tersebut dapat digunakan dalam penelitian.

Validitas menunjukkan sejauh mana instrumen yang digunakan untuk mengukur apa yang diukur. Pengujian validitas dilakukan dengan mengkorelasikan antara skor yang diperoleh pada masing-masing item soal dengan skor total individu. Pengolahan data untuk uji validitas ini dilakukan dengan bantuan komputer menggunakan program Microsoft Office Excel 2016. Dalam penelitian ini, pengujian validitas dilakukan terhadap 40 responden. Sedangkan untuk pengambilan keputusan dilakukan berdasarkan perbandingan dari $r$ hitung dan $\mathrm{r}_{\text {tabel}}$, dengan nilai $\mathrm{r}_{\text {tabel }}$ sebesar 0.312, $\mathrm{df}=38, \alpha=0.05$. Berdasarkan perhitungan yang telah dilakukan dan dari 20 butir kuesioner yang telah diuji coba, diperoleh kuesioner yang valid sebanyak 17 butir sesuai dengan yang ditunjukkan oleh tabel 3 .

Tabel 3. Hasil Perhitungan Uji Validitas Butir

\begin{tabular}{ccccc}
\hline No & Butir Soal & r hitung & r table & Keterangan \\
\hline 1 & 1 & 0.428 & 0.312 & Valid \\
2 & 2 & 0.524 & 0.312 & Valid \\
3 & 3 & 0.503 & 0.312 & Valid \\
4 & 4 & 0.061 & 0.312 & Tidak Valid \\
5 & 5 & 0.411 & 0.312 & Valid \\
6 & 6 & 0.541 & 0.312 & Valid \\
7 & 7 & 0.437 & 0.312 & Valid \\
8 & 8 & 0.348 & 0.312 & Valid \\
9 & 9 & 0.414 & 0.312 & Valid \\
10 & 10 & 0.639 & 0.312 & Valid \\
11 & 11 & 0.655 & 0.312 & Valid \\
12 & 12 & 0.556 & 0.312 & Valid \\
13 & 13 & 0.639 & 0.312 & Valid
\end{tabular}




\begin{tabular}{ccccc}
14 & 14 & 0.565 & 0.312 & Valid \\
15 & 15 & 0.660 & 0.312 & Valid \\
16 & 16 & 0.191 & 0.312 & Tidak Valid \\
17 & 17 & 0.751 & 0.312 & Valid \\
18 & 18 & 0.686 & 0.312 & Valid \\
19 & 19 & 0.717 & 0.312 & Valid \\
20 & 20 & 0.071 & 0.312 & Tidak Valid \\
\hline
\end{tabular}

Koefisien reliabilitas instrumen digunakan untuk melihat konsistensi jawaban item-item pernyataan yang diberikan oleh responden. Uji reliabilitas instrument dilakukan dengan bantuan Microsoft Office Excel 2016 dan software pengolah data SPSS yang disajikan pada tabel 4.

Tabel 4. Rekapitulasi Hasil Analisis Dengan Microsoft Excel 2010

\begin{tabular}{cccc}
\hline Nomor Soal yang Valid & Varian Tiap Butir & K & K-1 \\
\hline 1 & 0,37885 & 40 & 39 \\
2 & 1.32756 & 40 & 39 \\
5 & 0.41987 & 40 & 39 \\
6 & 0.53269 & 40 & 39 \\
7 & 1.93846 & 40 & 39 \\
8 & 0.37884 & 40 & 39 \\
9 & 0.54102 & 40 & 39 \\
10 & 0.26666 & 40 & 39 \\
11 & 0.99423 & 40 & 39 \\
12 & 0.43012 & 40 & 39 \\
13 & 0.4 & 40 & 39 \\
14 & 0.68653 & 40 & 39 \\
15 & 0.75897 & 40 & 39 \\
17 & 0.92243 & 40 & 39 \\
18 & 0.47115 & 40 & 39 \\
19 & 0.90705 & 40 & 39 \\
\hline Jumlah Varian & 1.16667 & 40 & 39 \\
\hline
\end{tabular}

Berdasarkan hasil perhitungan uji reliabilitas instrumen penilaian kemampuan berpikir kritis siswa pada mata pelajaran PPKn materi hak kewajiban dan tanggung jawab yang telah diuji coba, didapatkan koefesien reliabilitas sebesar 0,84 yang berada pada kategori sangat 
tinggi hal ini menujukan bahwa instrumen penilaian kemampuan berpikir kritis siswa pada mata pelajaran PPKn materi hak kewajiban dan tanggung jawab dinyatakan reliable.

\section{Pembahasan}

Pendidikan Pancasila dan Kewarganegaraan (PPKn) sangat penting dibelajarkan pada siswa SD untuk membentuk karakteristik dan kepribadian siswa yang cerdas sejak dini (Nusarastriya, 2013). Pembelajaran PPKn merupakan komponen pebelajaran yang memfokuskan siswa untuk memahami dan melaksanakan hak-hak dan kewajiban untuk menjadi warga negara yang cerdas dan berkarakter. Pembelajaran PPKn yaitu usaha sadar yang dilakukan secara ilmiah untuk memberikan kemudahan belajar pada siswa agar terjadinya internalisasi moral Pancasila dan pengetahuan untuk melandasi tujuan pendidikan nasional yang diwujudkan dalam perilaku sosial sehari-hari (Suhartono, 2018).

Pelaksanaan pembelajaran PPKn sangat penting untuk dibelajarkan kepada siswa SD untuk meningkatkan kesadaran siswa menjadi warga negara yang baik sejak dini (Nurmalisa et al., 2020). Tujuan Pendidikan Kewarganegaran adalah Partisipasi yang penuh nalar serta tanggung jawab dalam kehidupan politik dari warga negara yang taat pada nilai-nilai juga prinsip dasar demokrasi konstitusional Indonesia. Partisipasi warga negara yang efektif serta penuh tanggung jawab memerlukan penguasaan seperangkat ilmu pengetahuan, keterampilan intelektual dan keterampilan untuk berperan serta. Mengetahui kemampuan berpikir kritis yang dimiliki oleh setiap siswa diperlukan suatu penilaian disetiap akhir pembelajaran. Penilaian merupakan teknik untuk memperoleh informasi tentang kemajuan peserta didik di sekolah (Arifin, 2009; Rachmantika \& Wardono, 2019). Penilaian juga merupakan suatu proses pengumpulan data siswa yang dilakukan selama proses pembelajaran yang kemudian dianalisis. Hasil analisis tersebut kemudian dapat digunakan sebagai umpan balik (feedback) terhadap pembelajaran ataupun sebagai bahan pengambilan keputusan terhadap status siswa. Pada dasarnya, penilaian berperan sebagai program evaluasi proses, kemajuan belajar dan hasil belajar siswa (Docktor \& Heller, 2009; Mahdiansyah, 2019). Instrumen penilaian dapat dibagi menjadi dua yaitu instrumen tes dan instrumen non tes. Instrumen tes merupakan alat ukur yang berisi pernyataan atau soal yang harus dijawab dengan tepat. Yusuf, (2015)Tes merupakan suatu prosedur yang sepesifik yang digunakan untuk mengukur tingkah lakau seseorang. Instrumen non tes adalah penilaian yang dilakukan tanpa menguji peserta didik tetapi dengan melakukan pengamatan secara sistematis. (Dilla, 2019) Penilaian non tes merupakan penilaian yang mengukur kemampuan siswa secara langsung dengan memberikan tugas-tugas secara nyata dalam kegiatan pembelajaran.

\section{Conclusion}

Berdasarkan hasil penelitian dan pembahasan maka dapat disimpulkan bahwa dihasilkan produk pengembangan berupa instrumen penilaian kemampuan berpikir kritis siswa pada mata pelajaran PPKn materi hak kewajiban dan tanggung jawab kelas V SD Gugus I Kecamatan Sawan Tahun Pelajaran 2019/2020 yang "tepat". Ketepatan instrumen penilaian kemampuan berpikir kritis pada mata pelajaran PPKn ini dilihat dari hasil uji validitas yang menujukan bahwa pada uji validitas isi yang dilakukan kepada dua orang ahli (judges) menyatakan bahwa butir soal yang telah disusun berada pada kategori sangat tinggi yakni sebesar 1.00. dan dari uji validitas butir yang dilakukan terhadap 40 responden diperoleh $r$ hitung $>r$ tabel. yang menyatakan bahwa dari 20 butir soal yang telah diuji coba, terdapat 17 butir soal dinyatakan 
valid. Hasil uji reliabelitas instrumen kemampuan berpikir kritis pada mata pelajaran PPKn materi hak kewajiban dan tanggung jawab diproleh hasil sebesar 0,84 yang berada pada reliabilitas sangat tinggi.

\section{References}

Ahmad, S. (2013). Teori Belajar dan Pembelajaran di Sekolah Dasar. Kencana Prenada Media Group.

Amir, M. F. (2015). Proses berpikir kritis siswa sekolah dasar dalam memecahkan masalah berbentuk soal cerita matematika berdasarkan gaya belajar. Jurnal Math Educator Nusantara: Wahana Publikasi Karya Tulis Ilmiah Di Bidang Pendidikan Matematika, 1(2). https://ojs.unpkediri.ac.id/index.php/matematika/article/view/235

Antara, P. A. (2018). Stimulasi Metode Permainan Kreatif Berdesain Creative Movement Dan Budi Pekerti Dalam Mengembangkan Kemampuan Spasial Anak. Jurnal Pendidikan Anak Usia Dini, 12(1), 301-310. https://doi.org/10.2991/JPUD.122.11

Arifin, Z. (2009). Evaluasi pembelajaran (Vol. 8). Bandung: Remaja Rosdakarya.

Candiasa, I. M. (2010). Pengujian instrumen penelitian disertai aplikasi ITEMAN dan BIGSTEPS. Singaraja: Unit Penerbitan Universitas Pendidikan Ganesha.

Dilla, R. F. (2019). Penilaian Tes Di Tk Al-Fadhillah Kabupaten. 1(1), 94-110.

Dinni, H. N. (2018). HOTS ( High Order Thinking Skills ) dan Kaitannya dengan Kemampuan $\begin{array}{llll}\text { Literasi Matematikar Prisma, 170-176. } & \text { 1, }\end{array}$ https://journal.unnes.ac.id/sju/index.php/prisma/article/view/19597

Docktor, J., \& Heller, K. (2009). Robust assessment instrument for student problem solving. Proceedings of the NARST 2009 Annual Meeting, Garden Grove, CA, 1-19. https://groups.physics.umn.edu/physed/Talks/Docktor_NARST09_paper.pdf

Jufri, W. (2013). Belajar dan pembelajaran sains. Bandung: Pustaka Reka Cipta.

Kahar, M. S. (2017). Analisis Kemampuan Berpikir Matematis Siswa SMA kota Sorong terhadap Butir Soal dengan Graded Response Model. Tadris: Jurnal Keguruan Dan Ilmu Tarbiyah, 2(1), 11. https://doi.org/10.24042/tadris.v2i1.1389

Lestari, ria yuni, Tijan, \& Setiajid. (2013). Pengembangan Personal Skill Melalui Pembelajaran Pkn Di Sma Negeri 1 Pati. Unnes Civic Education Journal, 2(1). https://journal.unnes.ac.id/sju/index.php/ucej/article/view/1023

Mahdiansyah, M. (2019). Evaluasi Pelaksanaan Sistem Penilaian Hasil Belajar Siswa (Studi Kasus di Enam Kota). Jurnal Penelitian Kebijakan Pendidikan, 11(2), 48-63. https://doi.org/10.24832/jpkp.v11i2.224

Nurmalisa, Y., Mentari, A., \& Rohman, R. (2020). Peranan Pembelajaran Pendidikan Kewarganegaraan Dalam Membangun Civic Conscience. Bhineka Tunggal Ika: Kajian Teori Dan Praktik Pendidikan PKn, 7(1), 34-46. https://doi.org/10.36706/jbti.v7i1.10082

Nusarastriya, Y. H. (2013). Permasalahan Dan Tantangan Guru Pkn Menghadapi Perubahan $\begin{array}{lllll}\text { Kurikulum } & \text { (2013). } & \text { Satya }\end{array}$ https://doi.org/10.24246/j.sw.2013.v29.i1.p23-29

Suciasih, N. N. L., Mahadewi, luh putu putrini, \& Antara, putu aditya. (2019). Pengaruh 
Model Pembelajaran Dlps Terhadap Kemampuan Sains Permulaan Kelompok a Di Gugus Viii Kecamatan Buleleng. Jurnal Pendidikan Anak Usia Dini Undiksha, 7(2), 229. https://doi.org/10.23887/paud.v7i2.19000

Suhartono, E. (2018). Perubahan Pola Pembelajaran PKn yang Kontekstual ke Pola Kontekstual (CTL). Jurnal Teori Dan Praksis Pembelajaran IPS, 3(1), 1-12. https://doi.org/10.17977/um022v3i12018p001

Suwandi, \& Julianto. (2017). Penggunaan Metode Bermain Peran dalam Pembelajaran Ppkn untuk Meningkatkan Aktivitas Emosional Siswa Kelas Vb Sdn Putat Jaya Iii/379 Surabaya. Jurnal Penelitian Pendidikan Guru Sekolah Dasar, 05. https://www.neliti.com/publications/254676/penggunaan-metode-bermain-peran-dalampembelajaran-ppkn-untuk-meningkatkan-aktiv

Wibowo, A. P., \& Wahono, M. (2017). Pendidikan Kewarganegaraan: usaha konkret memperkuat multikulturalisme di Indonesia. Jurnal Civics: Media Kajian Kewarganegaraan, 14(2), 196-205. https://doi.org/10.21831/civics.v14i2.16043

Wijayanti, A. I., Pudjawan, K., \& Margunayasa, I. G. (2015). Analisis Kemampuan Berpikir Kritis Siswa Kelas V Dalam Pembelajaran IPA Di 3 SD Gugus X Kecamatan Buleleng. E-Journal PGSD Universitas Pendidikan Ganesha, 3(1), 1-12. file:///C:/Users/user/Downloads/37-5740-1-SM.pdf

Yusuf, M. (2015). Asesmen Dan Evaluasi Pendidikan Pilar Penyedia Informasi dan Kegiatan Pengendalian Mutu Pendidikan. In 1. Prenadamedia Group. 